\title{
Molecular detection of Campylobacter jejuni in archival cases of acute appendicitis
}

\author{
Lucas K Campbell ${ }^{1}$, Jennifer M Havens ${ }^{2}$, Margie A Scott ${ }^{2,3}$ and Laura W Lamps ${ }^{2}$ \\ ${ }^{1}$ Department of Pathology, University of Chicago, Chicago, IL, USA; ${ }^{2}$ Department of Pathology, University \\ of Arkansas for Medical Sciences, Little Rock, AR, USA and ${ }^{3}$ Department of Pathology, Central Arkansas \\ Veterans Healthcare System, Little Rock, AR, USA
}

\begin{abstract}
The role of enteric bacteria in the pathogenesis of acute appendicitis is a controversial subject. Campylobacter jejuni has been previously demonstrated in a minority of cases of acute appendicitis using microbiological or immunohistochemical methods, notably in cases where inflammation was limited to the mucosa/submucosa. Our goal was to evaluate cases of acute appendicitis for $C$. jejuni DNA using molecular methods, and to compare our findings to the histologic features. In total, $\mathbf{5 0}$ archival cases of acute appendicitis were selected, and PCR was performed using primers targeting a 286-bp fragment of the mapA gene specific to $C$. jejuni. Twenty histologically unremarkable appendectomy specimens served as negative controls. Cases were reviewed with attention to particular histological features including mucosal ulceration, cryptitis, depth of inflammatory infiltrate, and the presence of mural necrosis. Of acute appendicitis cases, $22 \%(11 / 50)$ were positive for $\boldsymbol{C}$. jejuni DNA by PCR analysis. Control cases were negative for $\boldsymbol{C}$. jejuni DNA. All patients presented with signs and symptoms typical of acute appendicitis. Of the $C$. jejuni positive cases, only $27 \%$ contained acute inflammation limited to the mucosa/submucosa, whereas the remainder had mural or transmural inflammation; therefore, the histological features of $\boldsymbol{C}$. jejuni-positive acute appendicitis cases were indistinguishable from C. jejuni-negative cases. In summary, $C$. jejuni DNA was detected in a significant percentage $(22 \%)$ of acute appendicitis cases, a much higher percentage than previous studies using other methodologies. As $C$. jejuni is an enteric pathogen that does not exist as a commensal or nonpathogenic organism, the presence of $C$. jejuni DNA implies current or recent infection. Further study is needed to determine whether the presence of $C$. jejuni DNA in acute appendicitis indicates appendiceal involvement by $\boldsymbol{C}$. jejuni enteritis, or if there is a true causative role for $\boldsymbol{C}$. jejuni in acute appendicitis.
\end{abstract}

Modern Pathology (2006) 19, 1042-1046. doi:10.1038/modpathol.3800640; published online 19 May 2006

Keywords: acute appendicitis; Campylobacter jejuni; polymerase chain reaction

The role of enteric bacteria in the pathogenesis of acute appendicitis has been, and remains, a subject of great debate. Bacteriologic studies, usually performed using microbiologic culture techniques, have revealed a wide variety of anaerobic and aerobic bacteria, ${ }^{1-3}$ but the possible contributions that these organisms might make to the pathogenesis of acute appendicitis remain unclear.

Campylobacter jejuni is the most commonly isolated stool pathogen in the US, affecting some 2 million people per year. Infection is generally associated with poorly prepared meat, especially poultry and beef, but has also been linked to other undercooked meats, untreated water, and unpas-

Correspondence: Dr LW Lamps, Department of Pathology, University of Arkansas for Medical Sciences, Shorey 4S/09, 4301 W. Markham, Slot 517, Little Rock, AR 72205, USA.

E-mail: lampslauraw@uams.edu

Received 5 April 2006; revised 18 April 2006; accepted 19 April 2006; published online 19 May 2006 teurized dairy products. The infectious dose is relatively low (approximately 500 organisms), and symptomatic disease usually presents as a selflimited gastrointestinal illness featuring abdominal pain, vomiting, diarrhea (often bloody), headaches, and fever. ${ }^{4-7}$

The presence of $C$. jejuni has been demonstrated in a minority of cases of acute appendicitis using microbiological and immunohistochemical techniques. Furthermore, these studies demonstrated that in appendices with evidence of $C$. jejuni infection, the acute inflammation was limited to the mucosa and submucosa, lacking transmural suppuration. ${ }^{8,9}$ These descriptions are histologically similar to the 'focal active colitis' pattern often seen in cases of acute, self-limited bacterial colitis, many of which are due to $C$. jejuni infection. ${ }^{10-14}$ Our goal was to retrospectively evaluate for the presence of $C$. jejuni using a recently developed molecular test, ${ }^{14}$ and compare the molecular results to the histological features. 


\section{Materials and methods}

\section{Case Selection}

A total of 50 cases diagnosed as acute appendicitis between the years of 2002-2004 were retrieved from the archives of the Department of Pathology at the University of Arkansas for Medical Sciences. All hematoxylin and eosin (H\&E) slides from each case were reviewed by two pathologists (LKC, LWL) and evaluated for the following histological features: mucosal ulceration, cryptitis, crypt abscesses, and mural necrosis. The depth of the acute inflammatory infiltrate was also evaluated, and designated as mucosal/submucosal if the infiltrate was limited to the mucosa/submucosa without extension into the muscularis propria; mural if the infiltrate extended into the muscularis propria; and serosal if the infiltrate extended through the muscularis to the serosa. For inclusion in the study, a neutrophilic infiltrate involving at least the mucosa and submucosa of the appendix and clinical symptoms characteristic of acute appendicitis before surgery had to have been present (ie, incidental appendectomy specimens and resections for tumor were excluded). Paraffin blocks corresponding to the H\&E slide showing the most robust inflammatory response were then chosen for subsequent DNA extraction and PCR analysis. Twenty histologically normal incidental appendectomy specimens served as negative controls.

\section{Molecular Testing}

Primers were designed using DNA sequence data for the map $A$ gene of $C$. jejuni, obtained from GenBank. The mapA gene encodes a $24-\mathrm{kDa}$ membraneassociated protein that is specific for $C$. jejuni. ${ }^{15}$ The primers target a 286-bp fragment of this gene present only in $C$. jejuni, and do not detect other Campylobacter species. The primers were tested against numerous other bacteria including Campylobacter coli, Yersinia enterocolitica, Yersinia pseudotuberculosis, Staphylococcus aureus, Enterococcus fecalis, Bacteroides fragilis, Pseudomonas aeruginosa, Proteus vulgaris, Enterobacter cloacae, Klebsiella pneumoniae, Escherichia coli, Shigella flexneri, Salmonella enterica, and Salmonella typhus. Results indicated that the primers were specific, as testing of the other bacteria generated no amplification product.

To determine the lower limit of detection of the assay, chromosomal DNA was isolated from pure cultures of $C$. jejuni. Bacterial suspensions were serially diluted, and a known aliquot of the dilution was plated on blood agar for colony counting; a corresponding aliquot was used for extraction of nucleic acids. PCR was then performed on aliquots of known concentration, and the lower limit of detection was 15 bacteria.
DNA was extracted from two $25 \mu \mathrm{m}$ sections cut from selected paraffin blocks from each case, following deparaffinization and proteinase $\mathrm{K}$ digestion at $55^{\circ} \mathrm{C}$ overnight. Reagent cocktails were made for each of the samples, including standard primers, buffers, and polymerases. Primers were $5^{\prime}$ end labeled with gamma- ${ }^{32} \mathrm{P}$ adenosine triphosphate, and DNA amplification was performed by PCR. A 99-bp fragment of the human beta-actin gene was used as a 'housekeeping gene' to ensure recovery of adequate, intact DNA from all samples. Purified CJ DNA from cultures was used as a positive control. Reagent blanks and the above mentioned 20 histologically unremarkable incidental appendectomy specimens served as negative controls. After amplification of DNA, gel electrophoresis was performed on each of the samples. Size separation of amplicons was performed on $8 \%$ native polyacrylamide gel followed by gel drying and autoradiography.

Sequence and restriction fragment length polymorphism analysis was performed to confirm that the PCR products matched the targeted sequences; sequences and restriction digestion patterns generated from our PCR products were homologous to published sequences and digestion patterns for the CJ mapA gene, respectively.

\section{Results}

\section{Molecular Analysis}

Of all the appendices tested, 22\% (11/50) were positive for CJ DNA by PCR analysis (Figure 1). All 20 histologically normal incidental appendectomy specimens were negative for $C$. jejuni DNA. Positive controls amplified without difficulty.

\section{Features of Cases Positive for C. jejuni}

Of the 11 cases positive for $C$. jejuni DNA, seven were men and four were women. Age ranged from 20 to 64 years (median 30 years). Bacterial cultures were performed in two of these cases: one case had positive abdominal wound cultures, yielding $E$. coli

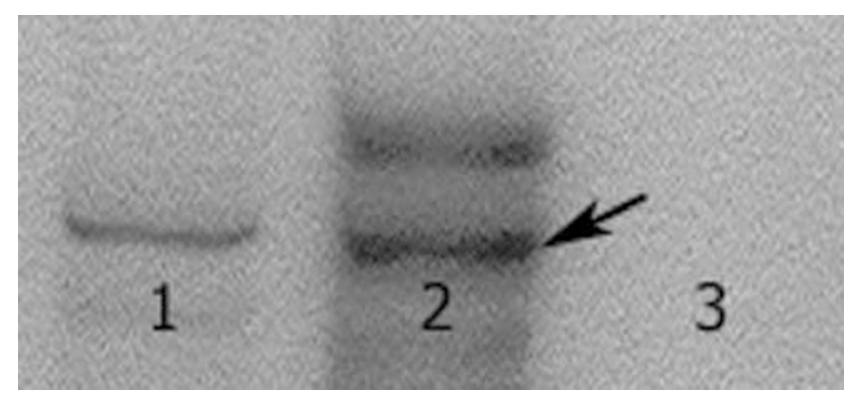

Figure 1 PCR gel showing detection of 287-bp fragment (arrow) of C. jejuni mapA gene in cases of acute appendicitis. Lane 1 is a case of acute appendicitis positive for CJ DNA. Lane 2 is a positive control (CJ DNA isolated from pure culture), and lane 3 is a negative control. 
Table 1 Histologic features of acute appendicitis cases positive for CJ DNA

\begin{tabular}{llccc}
\hline & $\begin{array}{l}\text { Depth of } \\
\text { inflammation }\end{array}$ & $\begin{array}{c}\text { Mucosal } \\
\text { ulceration }\end{array}$ & $\begin{array}{c}\text { Cryptitis/ } \\
\text { abcess }\end{array}$ & $\begin{array}{c}\text { Mural } \\
\text { necrosis }\end{array}$ \\
\hline 1 & M/SM & - & + & - \\
2 & M/SM & + & + & - \\
3 & M/SM & + & + & - \\
4 & Mural & + & + & - \\
5 & Serosal & + & + & + \\
6 & Serosal & + & + & + \\
7 & Serosal & + & NE & + \\
8 & Serosal & - & + & - \\
9 & Serosal & + & + & - \\
10 & Serosal & + & + & + \\
11 & Serosal & + & NE & + \\
\hline
\end{tabular}

$\mathrm{M} / \mathrm{SM}=$ mucosal $/$ submucosal; $\mathrm{NE}=$ no epithelium

and K. pneumoniae. Peritoneal fluid cultures were performed on one case, which were negative. No appendices were cultured at the time of resection. All patients presented with the typical signs and symptoms of acute appendicitis, including abdominal pain localizing to the right lower quadrant, nausea, and occasionally vomiting. No patients had diarrhea or prior colonoscopy. There was no seasonal preference among the $C$. jejuni-positive patients, with cases equally distributed throughout all seasons (three in winter, three in spring, three in summer, and two in the fall).

\section{Microscopic Findings}

The histological features of the $C$. jejuni DNApositive cases are summarized in Table 1. Briefly, all had cryptitis and/or crypt abscess formation. Of all C. jejuni-positive cases, $82 \%$ had mucosal ulceration (Figure 2), and $45 \%$ had mural necrosis (Figure 3). The depth of the inflammatory infiltrate was distributed as follows: three mucosal/submucosal (Figure 4), one mural, and seven transmural (Figure 5). The microscopic features did not differ significantly from the $C$. jejuni DNA-negative cases.

\section{Discussion}

This is the first study to demonstrate $C$. jejuni in acute appendicitis using molecular methods. $C$. jejuni DNA was detected in a significant percentage $(22 \%)$ of cases of acute appendicitis. As C. jejuni is an enteric pathogen that is not present in the alimentary tract as a commensal or nonpathogenic organism, ${ }^{4,16}$ the presence of $C$. jejuni DNA suggests current or recent infection in these patients. Furthermore, this study confirms that PCR analysis performed on routinely processed appendectomy specimens is a useful diagnostic method for detection of $C$. jejuni.

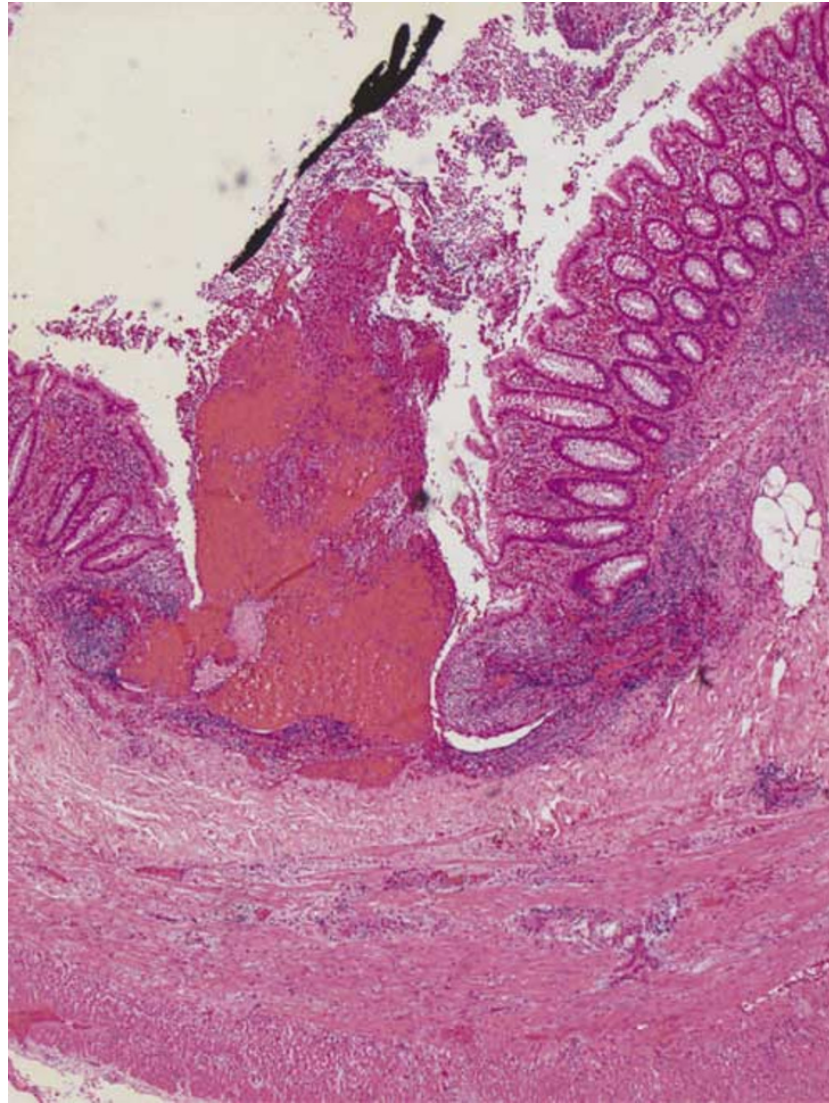

Figure 2 Mucosal ulceration in a CJ-positive appendix (H\&E, original magnification $\times 40$ ).

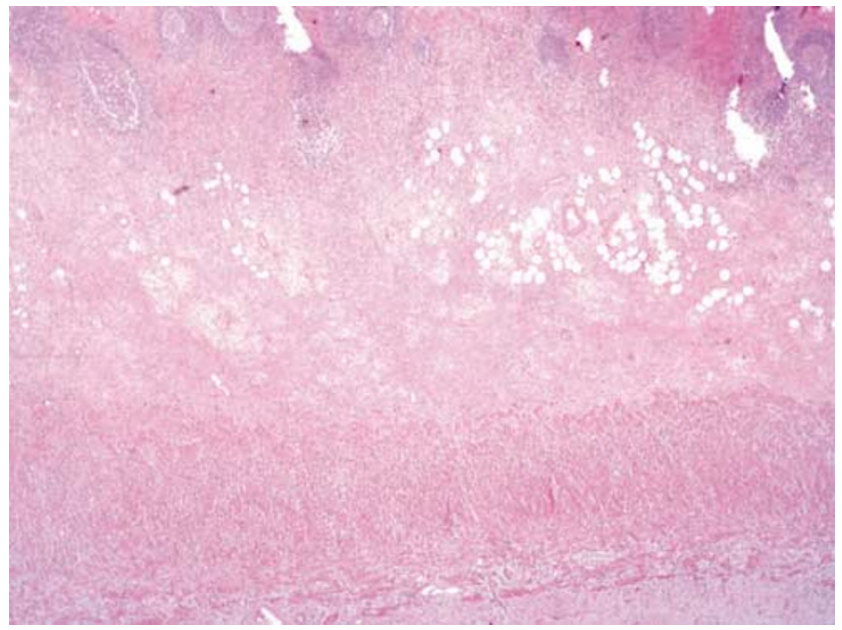

Figure 3 Mural necrosis in a case of acute appendicitis positive for $\mathrm{CJ}(\mathrm{H} \& \mathrm{E}$, original magnification $\times 20)$.

The etiology of acute appendicitis is probably multifactorial,,$^{3,17-20}$ and the putative role of enteric bacteria in the pathogenesis of acute appendicitis is very controversial. ${ }^{-3,21,22}$ Past studies, primarily using microbiologic culture techniques, have identified a wide-range of both aerobic and anaerobic bacteria, with Bacteriodes species being the most 


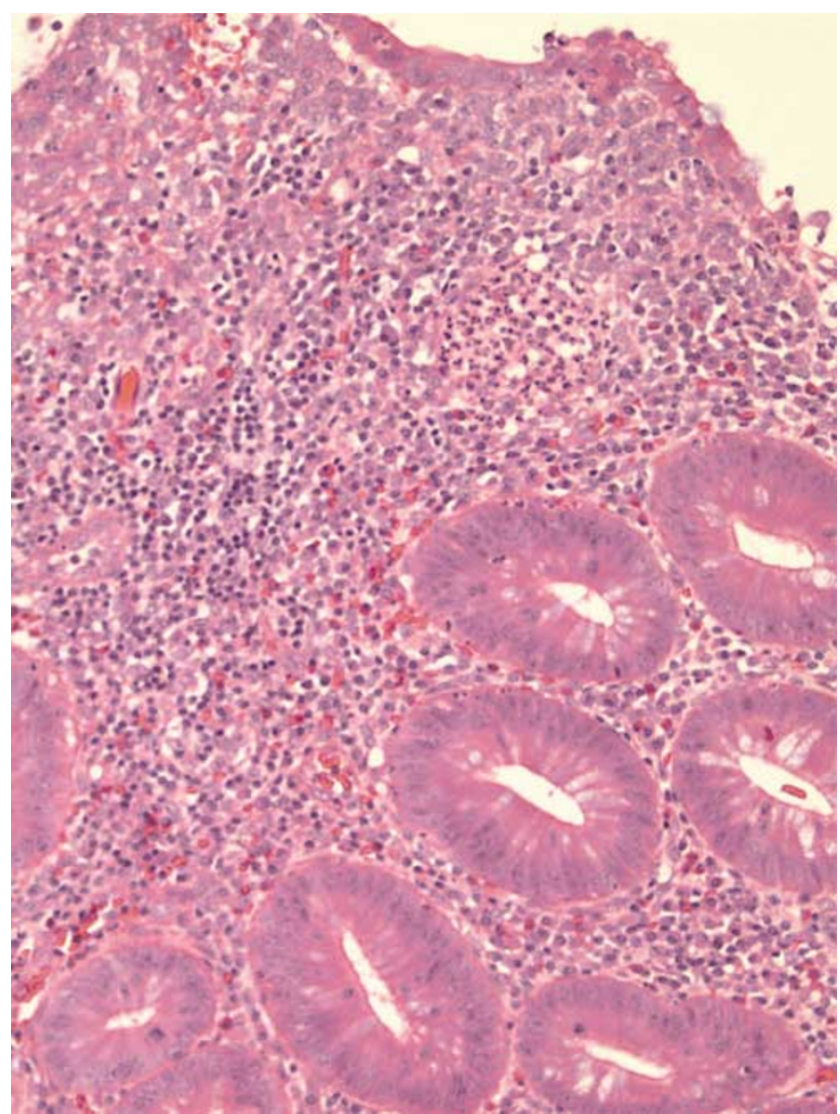

Figure 4 Neutrophilic infiltrate limited to the mucosa and submucosa in a CJ-positive appendix (H\&E, original magnification $\times 200$ ).

common isolate. ${ }^{1,21,23}$ Other organisms frequently isolated from acutely inflamed appendices include E. coli, Streptococcus species, and Enterococcus species. ${ }^{1-3,23}$ In contrast, $C$. jejuni has historically been isolated from only a minority of acute appendicitis cases. The two largest series examining the bacteriology of acute appendicitis using microbiologic culture techniques found that $0-2 \%$ of appendices harbored C. jejuni, ${ }^{8,23}$ and the largest series using immunohistochemical methods to detect $C$. jejuni in acute appendicitis found $C$. jejuni in only $2.5 \%$ of acute appendicitis. ${ }^{9}$ Although cultures and immunohistochemistry were not performed on our appendectomy specimens, and thus results are not available for comparison, the fact that we detected $C$. jejuni in a higher percentage of cases than previous studies (22\%) may indicate the superior sensitivity of PCR testing.

It has been previously suggested that appendices harboring acute inflammation limited to the mucosa/submucosa may indicate the presence of an enteric infection, rather than idiopathic 'nonspecific' acute appendicitis. ${ }^{17}$ In addition, previous studies detecting $C$. jejuni in acutely inflamed appendices have also found that the inflammation was limited to the mucosa, at least in their small number of cases. ${ }^{8,9}$ This pattern of injury is some-
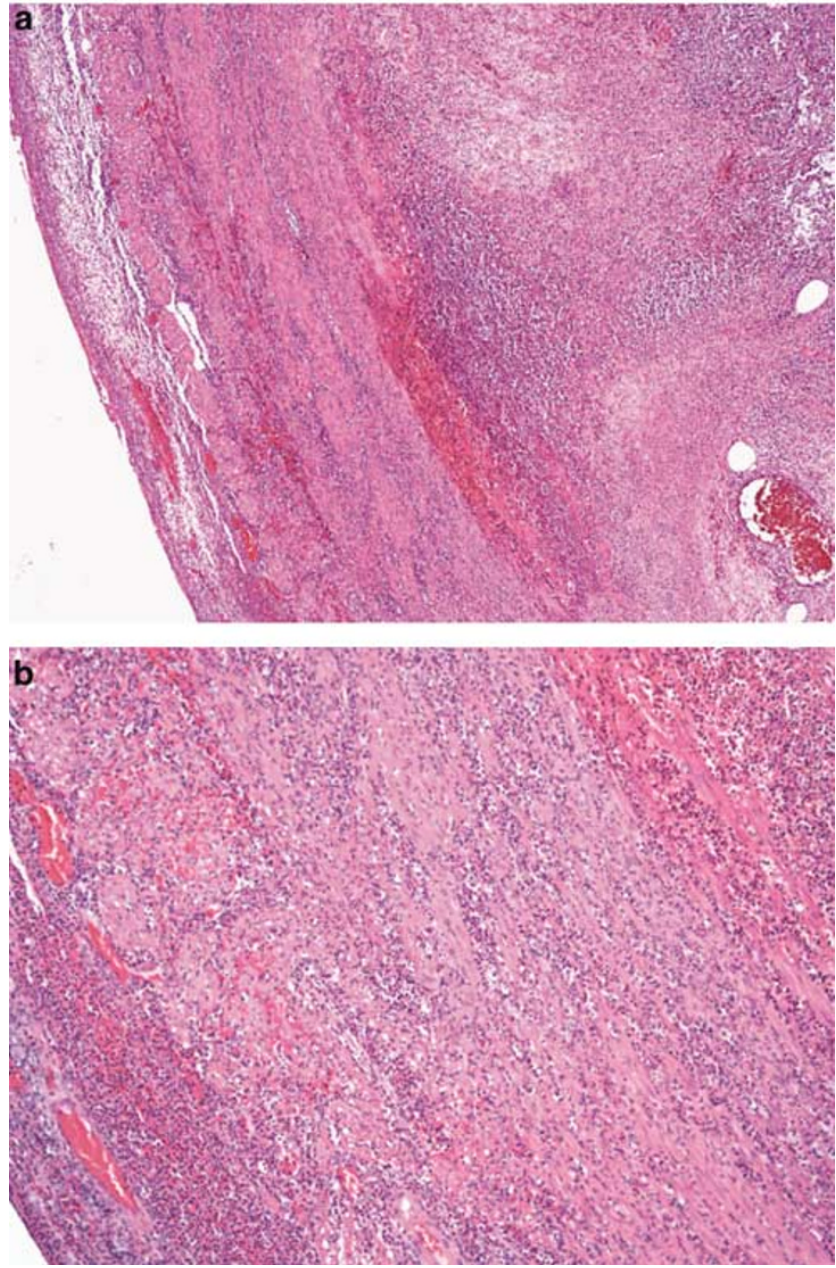

Figure 5 Transmural acute inflammation was seen in many cases of acute appendicitis harboring CJ DNA (H\&E; original magnification $\times 20(\mathbf{a})$ and $\times 100(\mathbf{b}))$.

what comparable to the 'focal active colitis' pattern seen in many of the bacterial colitides, including that due to $C$. jejuni infection. ${ }^{10-14}$ In a study of 116 acute appendicitis specimens, van Spreeuwel et al ${ }^{9}$ detected $C$. jejuni in three cases by immunohistochemical methods. These cases all showed acute inflammation limited to the mucosa, without transmural suppuration. These authors suggested that the histological changes seen in $C$. jejuni-associated acute appendicitis were limited to the mucosa and distinctly not associated with phlegmonous acute appendicitis. ${ }^{9}$ Van Noyen et $a l^{8}$ likewise detected C. jejuni in approximately $2 \%$ of 1244 acute appendicitis specimens using microbiological culture methods. Over half of the $C$. jejuni-positive appendices in their study were unremarkable, and $45 \%$ showed only mucosal inflammation. However, in our series, the majority of $C$. jejuni-positive appendices had inflammation that extended into the muscular wall of the appendix and beyond.

The significance of this contrast in histologic findings is not clear, nor is the significance of 
detecting $C$. jejuni in acute appendicitis using molecular methods. One possibility is that these patients had $C$. jejuni-related enterocolitis that involved the appendix; however, all of the $C$. jejuni positive patients presented with signs and symptoms typical of acute appendicitis, and none presented with fever or diarrhea that would indicate coexistent acute $C$. jejuni enterocolitis. However, this possibility cannot be excluded. A second possibility is that $C$. jejuni actually causes appendicitis in a minority of patients, in whom the histological features are indistinguishable from idiopathic nonspecific acute appendicitis. Superinfection of a previously inflamed appendix by $C$. jejuni is also conceivable. ${ }^{1,3,4}$ Further study is needed to assess the clinical and pathogenetic implications of the presence of $C$. jejuni DNA in acute appendicitis, but awareness of the possibility of $C$. jejuni infection in inflamed appendices is important, so that if postsurgical antibiotic therapy is necessary, the antimicrobial agents selected are appropriate. $^{3,17}$

In summary, we detected $C$. jejuni DNA in $22 \%$ of routine acute appendicitis specimens by PCR analysis. Furthermore, our C. jejuni-associated acute appendicitis specimens featured both acute inflammation limited to the mucosa/submucosa, and acute inflammation that extended into the wall of the appendix and beyond. Further study is needed to determine the significance of these findings, but pathologists and clinicians should be aware that $C$. jejuni is present in a minority of cases of acute appendicitis, and that PCR analysis is an excellent method for detection of $C$. jejuni in fixed, routinely processed tissues.

\section{References}

1 Jindal N, Kaur GD, Arora S, et al. Bacteriology of acute appendicitis with special reference to anaerobes. Indian J Pathol Micriobiol 1994;37:299-305.

2 Roberts JP. Quantitative bacterial flora of acute appendicitis. Arch Dis Child 1988;63:536-540.

3 Lamps LW. Appendicitis and infections of the appendix. Semin Diagn Pathol 2004;21:86-97.

4 Fields PI, Swerdlow DL. Campylobacter jejuni. Clin Lab Med 1999;19:489-503.

5 Altekruse SF, Stern NJ, Fields PI, et al. Campylobacter jejuni-an emerging foodborne pathogen. Emerg Infect Dis 1999;5:28-35.

6 Gillespie IA, The Campylobacter Sentinel Surveillance Scheme Collaborators. Point source outbreaks of Campylobacter jejuni infection: are they more common than we think and what might cause them? Epidemiol Infect 2003;130:367-375.

7 Melby K, Dahl OP, Crisp L, et al. Clinical and serological manifestations in patients during a waterborne epidemic due to Campylobacter jejuni. J Infect 1990;21:309-316.

8 van Noyen R, Selderslaghs R, Bekaert J, et al. Yersinia enterolitica and other enteric pathogens in patients with suspected appendicitis. Contrib Microbiol Immunol 1991;12:265-271.

9 van Spreeuwel JP, Lindeman J, Bax R, et al. Campylobacter-associated appendicitis: prevalence and clinicopathologic features. Pathol Ann 1987;22:55-65.

10 Price AB, Jewkes J, Sanderson PJ. Acute diarrhoea: Campylobacter colitis and the role of the rectal biopsy. J Clin Pathol 1979;32:990-997.

11 Kumar NB, Nostrant TT, Appelman HD. The histopathologic spectrum of acute self-limited colitis (acute infectious-type colitis). Am J Surg Pathol 1982;6: 523-529.

12 Price AB, Jewkes J, Sanderson PJ. Acute diarrhoea: Campylobacter colitis and the role of the rectal biopsy. J Clin Pathol 1979;32:990-997.

13 Surawicz CM, Haggitt RC, Husseman M, et al. Mucosal biopsy diagnosis of colitis: acute self-limited colitis and idiopathic inflammatory bowel disease. Gastroenterol 1994;107:755-763.

14 Schneider EN, Havens JM, Scott MA, et al. Molecular diagnosis of Campylobacter jejuni infection in cases of focal active colitis. Am J Surg Pathol (in press).

15 Stucki U, Frey J, Nicolet J, et al. Identification of Campylobacter jejuni on the basis of a species-specific gene that encodes a membrane protein. J Clin Microbiol 1995;33:855-859.

16 Blaser JM, Parsons RB, Wang WLL. Acute colitis caused by Campylobacter fetus ss. jejuni. Gastroenterol 1980;78:448-453.

17 Carr NJ. The pathology of acute appendicitis. Ann Diag Pathol 2000;4:46-58.

18 Williams RA, Myers P. Pathology of the Appendix and its Surgical Treatment, 1st edn. Chapman \& Hall: London, 1994.

19 Sisson RG, Ahlvin RC, Harlow MC. Superficial mucosal ulceration and the pathogenesis of acute appendicitis. Am J Surg Pathol 1971;122: $378-380$

20 Wangensteen OH, Bowers WF. Significance of obstructive factor in the genesis of acute appendicitis. Arch Surg 1937;34:496.

21 Pieper R, Kager L, Wentraub A, et al. The role of Bacteroides fragilis in the pathogenesis of acute appendicitis. Acta Chir Scand 1982;148:39-44.

22 Elhag EM, Alwan MH, Al-Adnan MS, et al. Bacteroides fragilis is a silent pathogen in acute appendicitis. J Med Microbiol 1986;21:245-249.

23 Rautio M, Saxen H, Siitonen A, et al. Bacteriology of histopathologically defined appendicitis in children. Pediatr Infect Dis J 2000;19:1078-1083. 